\title{
OS DIREITOS HUMANOS E O MUNDO MULTIPOLAR: ENTRE O UNIVERSALISMO E O PLURALISMO
}

\author{
Rita de Cássia Ferreira Lins e Silva ${ }^{1}$ \\ Pontifícia Universidade Católica do Paraná (PUC/PR) \\ (D) https://orcid.org/0000-0002-4037-3691
}

\begin{abstract}
RESUMO:
O presente artigo examina a relação entre as noções de direitos humanos e a política democrática em face de sua fundamentação filosófica, tendo em vista a noção do que se convencionou chamar de Nova Ordem Mundial. Nesta perspectiva, apresenta-se, pelas lentes da teoria da Democracia radical e plural, postulada por Chantal Mouffe, as condições para se pensar uma ordem baseada na concepção chave do pluralismo. Para tanto, problematizase os principais argumentos da versão cosmopolita diante do pressuposto de pretensões de validade universal, marcadamente presentes no pensamento de Jürgen Habermas enquanto obstáculo a uma política legítima dos direitos humanos. Esta leitura contribui para compreender as possibilidades dos avanços teóricos proporcionados pelo projeto multipolar proposto por Chantal Mouffe e identifica os principais obstáculos e meios possíveis para pensar uma política dos direitos humanos.
\end{abstract}

PALAVRAS-CHAVE: Direitos humanos; Cosmopolitismo; Multipolaridade; Pluralismo.

\section{HUMAN RIGHTS AND THE MULTIPOLAR WORLD: BETWEEN THE UNIVERSALISM AND THE PLURALISM}

\begin{abstract}
:
The aim of this article is to examine the relation between the notions of human rights and the democratic politics in the face of its philosophical foundation, in view of the notion called the New World Order. In this perspective, it presents, by the vision of the theory of radical and plural democracy postulated by Chantal Mouffe, the conditions to think about an order based on key concepts of pluralism. Therefore, it is argued the main

${ }^{1}$ Doutoranda em Filosofia pela Pontifícia Universidade Católica do Paraná (PUC/PR), Paraná - Brasil. Bolsista Capes. E-mail: linsesiilva@globo.com
\end{abstract}


arguments of the cosmopolitan version on the assumption of universal validity claims, notably in Jürgen Habermas's thinking as an obstacle to legitimate human rights. This reading helps to understand the possibilities of theoretical advances provided by the multipolar project proposed by Chantal Mouffe and it identifies the main obstacles and possible ways to think a politics of human rights.

KEYWORDS: Human rights; Cosmopolitanism; Multipolarity; Pluralism.

\section{Introdução}

No âmbito da filosofia política contemporânea, a temática dos direitos humanos é revista por Chantal Mouffe a partir do que ela denomina de projeto multipolar. Esta ideia representa, em última análise, a possibilidade de renovar as discussões acerca do cosmopolitismo (MOUFFE, 2009). ${ }^{2}$ Trata-se do reconhecimento da natureza pluralista do mundo perante uma ordem mundial multipolar, que se opõe ao esvaziamento da dimensão antagônica do político, à moralização da política, que supõe uma estabilização imediata dos direitos humanos a partir de consensos universais, tal como entende, a autora, defender Jürgen Habermas. ${ }^{3} \mathrm{O}$ que está em jogo é a noção de universalidade que exclui os aspectos da identidade e da alteridade, necessários para a composição de uma política democrática dos direitos humanos.

De tal modo, o objetivo do presente artigo se centra na categoria dos direitos humanos e da democracia tratados à luz de seus fundamentos filosóficos diante das múltiplas identidades políticas ${ }^{4}$. Trata-se da necessidade teórica de buscar novas alternativas distanciadas de um conteúdo moral universal, que transcenda as diferentes demandas democráticas características da pluralidade de formas de vidas e posições de sujeitos.

O modelo teórico, de caráter universalista, representa um distanciamento do direito, enquanto perspectiva de mundo ideal, e das novas identidades, enquanto perspectiva de mundo real no conflitivo mundo das relações de poder. Esse é o sentido que move a problemática aqui trazida, traduzida pelo enfrentamento aos desafios atuais acerca da relação entre política democrática e direitos humanos, o que requer reconhecer, teoricamente, a natureza constitutiva do pluralismo, no sentido de refletir acerca das condições para a sua fundamentação dentro de uma ordem

\footnotetext{
${ }^{2}$ MOUFFE, Chantal. En torno a lo político. Buenos Aires: Fondo de Cultura Económica, 2009.

3 Jürgen Habermas é um filósofo e sociólogo alemão, da segunda geração da Escola de Frankfurt.

${ }^{4}$ HABERMAS, Jurgen. Direito e democracia: entre facticidade e validade. Tradução de Flávio Beno Siebeneichler. Rio de Janeiro: Tempo Brasileiro, 1997.
} 
mundial. Nestes termos, questiona-se acerca do modo como se pode pensar uma política dos direitos humanos na perspectiva do pluralismo democrático radical defendido por Chantal Mouffe.

Daí a importância de trazer ao centro do debate as discussões de Mouffe acerca de um projeto multipolar em oposição a versões cosmopolitas, tal como a sustentada por Habermas, e que possibilite, ainda, maiores especulações de ordem teórico-analítica acerca do pluralismo como base para pensar os fundamentos dos direitos humanos em face dos novos sujeitos - característicos das novas formas de vidas e de lutas enfrentadas no polo internacional.

\section{Multipolaridade e pluralismo}

Uma multipolaridade requer pensar a existência de diferentes centros de decisões, em contraposição ao intento cosmopolita de um mundo ordenado por unidades internacionais centralizadoras, que supõem a unificação dos valores e do poder. Perspectiva, pois, em que se propõe pensar a articulação entre diferentes subjetividades políticas manifestadas na dimensão do conflito que, para Mouffe, representa a própria natureza ontológica do político.

O pluralismo democrático relacionado à temática dos direitos humanos traz à luz um dos pontos de embate entre as versões cosmopolitas, sobretudo aquela tratada por Habermas e a ideia de multipolaridade de Mouffe, no que se refere aos ideais de representação democrática. O que, certamente, tem a ver com a inserção dos excluídos no mundo visível, ou seja, de pensar a inclusão a partir daqueles que podem ser percebidos como excluídos à luz dos valores morais considerados válidos. Uma política democrática dos direitos humanos não pode anular o pluralismo, cuja proposição segue para além de uma simples retórica acerca de modelos pacificamente aceitos no plano universal.

Tal perspectiva, demanda a necessidade teórica de explicitar os incômodos que deixaram no mundo, especialmente na dimensão das novas identidades políticas, a dúvida acerca da possibilidade, ou não, dos direitos humanos serem exequíveis numa perspectiva cosmopolita, já que a invenção ocidental desses direitos traduz, em tese, uma equivalência de valores e de direitos (uníssonos), como se um só diapasão pudesse transpor o mundo plural. Ou seja, inquieta o fato de que as novas identidades postulam pela congruência entre realidade e teoria. Trata-se de um mundo real que possibilite um ideal concreto e mutável, e não disfarçado, sob vestes legais, cuja tendência é a de unificar os valores sob um ponto de vista ideal.

De tal modo, argumentamos que a fundamentação dos direitos humanos, pensada a partir de uma proposta de validade universal, como declarada por versões cosmopolitas, a despeito de sua aplicabilidade no âmbito exclusivo da moral, pode ser inexequível. A razão disso está no fato 
de as realidades plurais poderem colidir, de forma negativa, com as novas identidades políticas, a dar lugar à promoção de novas desumanizações, evidenciadas, sobretudo, no contexto da violência.

Assim, entende-se que a validade dos direitos humanos não condiz com um sistema de universalidade, antes deve ser pensada à luz das múltiplas subjetividades que revelam práticas concretas. Afirma-se, pois, que a partir do reconhecimento do pluralismo se pode pensar a fundamentação dos direitos humanos apoiada na dimensão antagônica do político, colocando em relevo os aspectos da identidade e da alteridade. Essa ideia vem compor uma política radicalmente democrática que pode sustentar, no âmbito supranacional, as condições da validade de direitos.

Entende-se que a concepção acerca dos Direitos Humanos em voga na atualidade é, no mínimo, uma compreensão rasa dos princípios, normas, valores e critérios constitutivos dos fundamentos reais da democracia enquanto princípio que reza a Constituição política e jurídica. De tal modo, os défices e as debilidades democráticas em face do exercício e efetividade dos direitos passam a existir, como apontam Costas Douzinas e Emanuel Lévinas, como adiante veremos. O sentido disso está em fomentar o pensamento filosófico da política e do direito para o enfrentamento de novas possibilidades em torno das vulnerabilidades políticas e sociais que retiram o sujeito de seu eixo central: a política.

O ponto central está na proposta de radicalização democrática plural dos direitos humanos trazida por Mouffe, que se distancia de autores como Habermas. Este último se prende ao resgate do discurso filosófico do direito e da moral, de inspiração kantiana, como forma de recuperar o projeto político do século XVIII (MOUFFE. 1999, p. 12), em contraposição ao que Mouffe compreende enquanto renovação do projeto democrático da modernidade. Para a autora, a perspectiva de democracia radical e plural assume a proposta de "tentar prolongar e aprofundar a revolução democrática iniciada no século XVIII [...]" (MOUFFE; LACLAU, 1987, p. 06) sendo esse aprofundamento referenciado à "multiplicidade e diversidade das lutas políticas contemporâneas". 5

A revolução democrática iniciada no século XVIII, pensada do ponto de vista formal dos direitos dirigidos à pessoa humana, na perspectiva do Estado de Direito, representa o legado às articulações do ideal democrático do século XIX e XX. Nesse contexto, a tentativa de Mouffe em aprofundar o projeto político da modernidade deve-se ao fato de que por um lado, os pressupostos universalistas abstratos dos direitos humanos foram resgatados por versões cosmopolitas que acabaram por negar a pluralidade do mundo e, por outro, pela linha assumida por aqueles que defendem o particularismo em oposição ao universalismo, resultando em outra forma de essencialismo (MOUFFE. 1999, p. 137).

${ }^{5}$ Ibid.

Os direitos humanos e o mundo multipolar: entre o universalismo e o pluralismo - Rita de Cássia Ferreira Lins e Silva 
Para a autora, "a reformulação do projeto democrático em termos de democracia radical requer o abandono do universalismo abstrato do iluminismo, que se referia a uma natureza humana indiferenciada". ${ }^{6}$ As primeiras teorias da democracia moderna (ou democracia liberal), e do indivíduo como portador de direitos se concretizaram diante desta abstração, como está claro na Declaração de Independência Norte Americana (1776) e na Declaração dos Direitos do Homem e do Cidadão (1789). Declarações inspiradas pela filosofia política e do direito racional moderno, que refletem as concepções de direito natural pensado à época. Sobre isso, declara Douzinas, que os Direitos Humanos passam a ter uma característica de abstração em relação ao indivíduo (DOUZINAS. 2009. p. 384).

Mouffe, em consonância com a crítica já referida por Douzinas, expõe que não se pode mais pensar na essência abstrata de um universalismo que não alcança a manifestação concreta dos diferentes tipos de práticas. Não se trata de rechaçar o universalismo ou o particularismo, mas de compreender uma "nova forma de individualidade verdadeiramente plural e democrática" (MOUFFE. 1999, p. 42). Uma individualidade que se assimila à compreensão de Wittgenstein acerca dos diferentes jogos de linguagem relacionada aos diferentes mundos. Assim, uma política democrática radical plural dos direitos humanos deve assumir, na instância supranacional, a manifestação concreta das diferentes formas de vidas.

A interpretação de Mouffe acerca da problemática dos direitos humanos não supõe a ideia de um relativismo, e esse é o ponto. Como já afirma Wolfgang Kersting, o pluralismo é incompatível com o relativismo na medida em que pode gerar novos tipos de sectarismo (KERSTING. 2003, p. 84). Mas, também, não assume o caráter proposto por Kersting, de uma linguagem normativa universal comum, se assim o fosse, seria o mesmo que retomar o discurso de uma moral universal. Trata-se antes, de pensar as articulações políticas possibilitadas pelas novas identidades expressas em suas particularidades frente ao que se postula por universal.

\section{A pretensão de validade habermasiana}

Mouffe contraria o intento habermasiano quanto ao seu pressuposto fundamental de pretensões de validade universal $^{7}$ para pensar o

\footnotetext{
${ }^{6}$ Ibid., p. 32.

7 A questão da validade em Habermas, remete-se a um acordo alcançado entre os participantes do espaço público, onde se busca um consenso válido - medido por pretensões de validade suscetíveis de crítica. Estas pretensões fundamentam-se no mundo objetivo, social e subjetivo. São três as pretensões de validade elencadas: verdade, correção e veracidade - assim, o ouvinte deve ter razões para: a) aceitar (rejeitar ou questionar) um conteúdo exposto como verdadeiro (modo constativo da força ilocucionária); b) uma ordem como legítima (modo regulativo da força ilocucionária); e uma proposição como sincera (modo expressivo da força ilocucionária). O conhecimento de tais condições permite ao ouvinte definir seu posicionamento em termos de aceitação ou rejeição de determinada
} 
cosmopolitismo. Para desenvolver este argumento faz-se necessário uma introdução dos principais pontos de embate que aludem à ideia de cosmopolitismo e multipolaridade.

Mouffe e Habermas começam a desenvolver suas linhas de pensamento a partir de críticas e assimilações a determinados posicionamentos de Carl Schmitt. ${ }^{8}$ Para ambos, o principal problema de trabalhar com Schmitt deve-se a relação amigo/inimigo, relacionado a uma concepção de homogeneidade referenciada à nação, a partir da qual Schmitt desenvolve seus argumentos acerca do teor impositivo de uma moral universal.

Para Habermas, a crítica a um direito cosmopolita, da qual se ocupa Schmitt, deve-se ao conceito de amigo/inimigo que o permite, reiteradamente, criticar as ações das Nações Unidas quanto às penalizações de uma ordem moral aplicada no plano internacional (HABERMAS. 2002. p. 218). Na concepção de Schmitt, "é o universalismo da moral da humanidade" que está por traz das ações violentas de intervenção humanitária. Neste sentido, para Habermas, Schmitt segue erronemante a mesma compreensão de H. M. Enzensberger, que trata da retórica do universalismo como algo exclusivo dos valores morais do ocidente, impostos de forma indiscriminada à todas às nações, ao ponto de afirmar que "o universalismo se revela como uma armadilha moral". 10

Contrariamente, Habermas sustenta que "a legitimação democrática do direito deve garantir que este esteja em sintonia com as proposições morais já reconhecidas" (HABERMAS. 2002, p. 224). O autor supõe que o direito cosmopolita somente se constrói para além das fronteiras do Estado associado, o que se dá, ao mesmo tempo, na relação entre direito e moral no plano da política internacional. Assim, seguindo o pensamento de K. Gunther, a resposta em relação aos perigos da moralização "não é isentar a política de uma dimensão moral, mas sim transformar a moral, por via

norma. O sucesso do ato ilocucionário depende do assentimento, ou seja, do entendimento, entre os participantes acerca do que está sendo proferido no momento da comunicação. Entretanto, atos perlocucionários podem ter sucesso no momento em que aquele que está falando se utiliza de fins locucionários para convencer outrem, o que ocorre quando esse não expõe seus reais objetivos estratégicos. A linguagem passa a ser considerada como um medium universal de incorporação da razão. De modo que o entendimento linguístico, como mecanismo de coordenação da ação, passa orientar o agir por pretensões de validade (universais) na manutenção da ordem social. O que se dá a partir do reconhecimento de pretensões de validade normativa. Cf. HABERMAS, Jurgen. [1981]. Teoría de la acción comunicativa. Tradução de Manuel Jiménez Redondo. Tomo I. Madrid: Taurus, 1987.

${ }^{8}$ SCHMITT, Carl. The concept of the political. New Brunswick: Rutgers, 1976.

${ }^{9}$ Ibid., 2002, p. 222.

${ }^{10}$ ENZENSBERGER, Hans Magnus. Visões da guerra civil. In: Guerra civil. São Paulo: Cia das Letras, 1995. 
democrática, em um sistema positivado de direitos, dotado de procedimentos jurídicos para sua aplicação e imposição"11.

Essa transformação da moral é advertida por Lévinas, no sentido da manipulação do poder político. Trata-se de uma moral que pode não alcançar o que o autor expõe ser uma das bases de fundamentação dos direitos humanos: a alteridade, que é constitutiva da identidade (LÉVINAS. 1993, p. 98). Se o 'Eu' encontra a expressão de sua identidade no outro, Lèvinas compreende que nessa relação não pode existir o desejo pelo poder de dominação diante de sua absoluta diferença, o que poderia resultar na ideia de uma moral universal referente aos valores da humanidade (LEVINAS. 1987, p. 60).

Posto isso, segue-se com o questionamento de Habermas quanto ao tratamento às reivindicações por reconhecimento das identidades coletivas ou igualdade de direitos para as formas de vida culturais distintas (HABERMAS. 2002, p. 231). Ele se refere, por exemplo, aos movimentos "feministas, as minorias em sociedades multiculturais, povos que anseiam por independencia nacional ou regiões colonizadas no passado e que reclamam igualdade no cenário internacional". ${ }^{12}$

Para Habermas, os direitos humanos podem ser fundamentados de um ponto de vista moral, desde que, para tanto, se assuma os procedimentos democráticos. Ou seja, desde que os atingidos por determinada norma possam se manifestar em relação à ela, e assumam a reciprocidade de pretensão universal para sua validação. ${ }^{13}$ Entretanto, aqui pode se questionar, levando em consideração à afimação de Habermas acerca das minorias nacionais que "lutam impiedosamente entre si", ${ }^{14}$ a ideia de que uma fundamentação moral universal em face dos direitos humanos poderia eclodir como formas de violência política.

A posição de Habermas, e que fica clara em seu discurso acerca da cooriginariedade entre direitos humanos e soberania do povo, é que o princípio da democracia não pode ser subordinado ao princípio moral, pois o primeiro somente tem como finalidade a instituição de procedimentos de normatização legítima do direito (HABERMAS, 1997, p. 122). Entretanto, expõe o autor que questões morais, por sua complementariedade ao direito, devem ser incorporadas ao ordenamento jurídico sem a oneração de trazer à cena normativa o plano cultural, pois não se relaciona a uma verdade objetiva.

Ao passar as normas de ação moral para o ordenamento jurídico à luz do princípio democrático, Habermas supõe o necessário distanciamento de uma consciência moral do sujeito. Nesse sentido, se deve desacoplar "o

${ }^{11}$ GUNTHER, Klaus. Der Sinn für Angemessenheit. Anwendungsdiskurse in Moral und Recht. Frankfurt: Suhrkamp, 1988.

${ }^{12}$ Ibid., p. 231.

${ }^{13}$ Ibid., p. 293.

${ }^{14}$ Ibid., p. 247. 
plano da cultura política do plano das subculturas e de suas identidades" (HABERMAS. 2002, p. 135). De modo que, no âmbito de uma ordem mundial se possa pensar o direcionamento das forças vinculativas normativas dirigidas por órgãos internacionais como as Nações Unidas, que ganha força jurisdicional, inclusive dotada de força policial. ${ }^{15}$

Nesse sentido, importa que haja uma devida atualização dos conteúdos das declarações, e um novo posicionamento dos órgãos internacionais, pois não se pode coadunar facilmente com a ideia de que os direitos universais devam estar completamente desacoplados das especificidades que norteiam as diferentes formas de vida, como propõe Habermas. Do contrário, certamente levaria a sua mumificação, com fórmulas cada vez mais solenes e ao mesmo tempo vazias (BOBBIO. 1991, p. 50).

Para Mouffe, o discurso de Habermas somente reforça a convicção de que as sociedades ocidentais são a encarnação do melhor regime, e que tem a missão civilizadora de universalizá-lo (MOUFFE. 2009, p. 89). Disso, segue a afirmação de que "os direitos humanos, como sustenta Habermas, tem duas faces: por um lado, há um conteúdo moral universal; por outro, há forma de direitos legais; daí, a necessidade destes de serem encarnados em uma ordem legal (...)" 16 no sentido de que "todas as sociedades estão destinadas a adotar padrões ocidentais de legitimidade e sistemas legais baseados nos direitos humanos, independentemente de sua base cultural". ${ }^{17}$ Essa é a natureza antipolítica do discurso habermasiano que retira de cena o pluralismo do mundo.

A crítica lançada por Mouffe pode ser lida mais claramente no posicionamento de Costas Douzinas ao afirmar que a própria noção de humanidade não possui um sentido estático e não pode, portanto, ser considerada como fonte de regras morais ou legais que se pretendem únicas. ${ }^{18}$ A noção de humanidade, expõe o autor, é utilizada há tempos como uma estratégia de classificação ontológica sem antes conceber o significado mesmo que pode alcançar o sentido de humanidade e desumanidade. Daí o seu questionamento: "temos direitos humanos porque somos todos humanos, mas sabemos definir o que é humano?". 19

Essa classificação ontológica fixa, também é questionada por Mouffe, pois exclui o sentido de indeterminação e ainda, impõe a determinação de valores morais universais intransponíveis no tempo e no espaço. Significa dizer que tudo aquilo que transpõe a realidade concreta do

\footnotetext{
15 Ibid., p. 149.

${ }^{16}$ Ibid., p. 92.

${ }^{17}$ Ibid., 2009, p. 92.

${ }^{18}$ DOUZINAS, Costas. Os paradoxos dos direitos humanos. Tradução de Caius Brandão. Revista Anuário. Pensar os direitos humanos: desafios à educação nas sociedades democráticas, v. 1, n.1, 2001.

${ }^{19}$ Ibid., passim.
} 
suejito, universalizando-o, representa a anulação do político. Perspectiva assumida pelo cosmopolitismo, pois é justamente o que ele produz: a caracterização da negação do político. O modelo liberal democrático, no qual se baseiam as versões cosmopolitas, encarna seu triunfo no direito baseado em uma razão universal, que ocupa o lugar da política. Sendo, pois, a questão fundamental "a elaboração de procedimentos necessários para a criação de um consenso supostamente baseado em um acordo racional" (MOUFFE. 1999, p. 12).

Assim, é necessário ultrapassar os modelos engessados do cosmopolitismo e aceitar o estabelecimento de um mundo multipolar, que requer a existência de uma pluralidade de centros de decisões. O que significa, como já apontava Massimo Cacciari, ${ }^{20}$ à quem Mouffe recorre para traçar sua ideia de projeto multipolar, "trabalhar pelo estabelecimento de um sistema de direito internacional baseado na ideia de polos regionais e identidades culturais federadas entre sí no reconhecimento de sua autonomia total" (MOUFFE. 2009, p. 124).

Para desenvolver suas ideias Mouffe declara a impossibilidade habermasina de supor um consenso sem exclusões. A autora baseia seus argumentos em prol do que denomina de agonismo pluralista, com base, e, em oposição, a versão antagônica amigo/inimigo proposta por Schmitt, a lhe permitir trabalhar a noção de relação adversarial. O distanciamento em relação à Schmitt deve-se ao fato de que, para este autor, "a democracia requer a existência de um Demos homogêneo e isto impede a possibilidade do pluralismo". ${ }^{21}$

O resgate da dimensão antagônica do sujeito deve ser pensado sob um viés crítico, no sentido de colocar em tela as diferentes formas de identidades que reafirmam o pluralismo sob o lastro de uma concepção ativa do sujeito político. O político representa a própria dimensão do antagonismo, pois envolve o contexto da alteridade e da diferença, constitutivas das sociedades plurais. Essa é a chave para "questionar a ideia de universalidade dos direitos humanos como é geralmente entendida" (MOUFFE, 2009, p. 133).

Para Mouffe, há uma multiplicidade de identidades quando não existe um denominador comum. Não se trata de um 'pluralismo extremo', em que há a valorização extremada das diferenças ao ponto de gerar sectarismos. Trata-se de um pluralismo característico da existência de diferentes identidades políticas (MOUFFE. 2003, p. 37-38).

\footnotetext{
${ }^{20}$ CASSIARI, Massimo. Digressoni su Impero e ter Rome. In: H. Frise; A. Negri; P. Wagner (eds). Europa política ragioni di una necessita. Roma: Manifestolibri, 2002.

21 MOUFFE, Chantal. La paradoxa democrática. Traducción de Tomás Fernández e Beatriz Equibar. Barcelona: Gedisa, 2003.
} 
Essa é uma noção de identidade apoiada em Henry Staten, que trata da noção de 'exterior constitutivo'. ${ }^{22}$ Essa noção permite à Mouffe afirmar que na ordem do jogo político adversarial, o sentido da possibilidade de um 'Eles' - na qualidade de um exterior constitutivo, formador da identidade, com base na diferença -, ameaça o modo de ser de uma sociedade política determinada. Nessa relação, as partes são consideradas como legítimas. Caso contrário, tem-se o esfacelamento da política, o que pode gerar novas formas de violência, em que o inimigo deve ser exterminado.

A concepção de identidade delineada por Mouffe está intrinsecamente relacionada ao que ela denomina de hegemonia, concepção que norteia o entendimento da autora acerca de um projeto multipolar em oposição ao cosmopolitismo. Trata-se de uma ideia centrada na possibilidade de que diferentes identidades políticas empreendam suas forças contra a imposição de poderes arbitrários que pretendam obstruir seu referencial de mundo de modo que, a "configuração mesma das relações de poder em torno das quais se estrutura uma determinada sociedade seja uma luta entre projetos hegemônicos opostos que nunca podem reconciliar-se de um modo racional" (MOUFFE. 2009, p. 28).

Essa afirmação está em consonância com o pensamento de Douzinas, para quem os sistemas sociais e políticos tornaram-se homogêneos, supondo prioridades ideológicas que se transformam em valores e princípios universais. Os direitos humanos, afirma o autor, é o objeto principal destas especulações, e se concretiza no âmbito do direito internacional. Quando tratados sob esta perspectiva, considerando a expressão de Jacques Rancière quanto à ideia que traduzimos por parte de nenhuma parte, torna-se mais claro o antagonismo sob a face dos excluídos da ordem social, os "invisíveis fora do sentido estabelecido do que existe e é aceitável". ${ }^{23}$

O sentido de hegemonia colocado por Douzinas, frente a dominação política que impõe valores e princípios universais, é tratado por Mouffe sob o signo da hegemonia liberal. O que deve ser confrontado por novas hegemonias, às quais não implica o sentido clássico de dominação, mas sim uma articulação entre diferentes identidades que não possuem qualquer caráter pré-determinado. Esse empreendimento é necessário para que a união de forças hegemônicas deponha contra sistemas de normas que se apresentem de forma inflexível diante da diversidade de valores histórico e socialmente construídos.

De tal modo, é possível pensar certa autonomia com relação aos espaços onde são constituídas as articulações capazes de produzir uma cadeia de equivalência que se entrecruza com outros espaços políticos de luta democrática. O que perfaz a ideia de que "a única estratégia concebível

${ }^{22}$ STATEN, Henry. Wittgenstein and Derrida. Lincoln : University of Nebraska Press, 1984.

${ }^{23}$ DOUZINAS, 2001, passim. 
a dependência mundial de um só poder é encontrar modos de pluralizar a hegemonia" (MOUFFE. 2009, p. 125). E isso, continua a autora, somente é possível "mediante o reconhecimento de uma multiplicidade de poderes regionais". ${ }^{24}$ O que, certamente, reforça a ideia de um pluralismo reconhecido em suas diferenças, ou, dentro de uma lógica mais comum, trata-se uma perspectiva da particularização do universal.

\section{Considerações finais}

Os posicionamentos defendidos por Mouffe se traduzem como uma forma efetiva de desafiar as relações de poder a partir de um projeto hegemônico capaz de desarticular as práticas existentes sob o signo da hegemonia liberal através da criação de novos discursos e instituições. Trata-se do estabelecimento de novas hegemonias, pois. O que implica em uma cadeia de equivalências entre a diversidade de lutas democráticas. ${ }^{25}$ Esta perspectiva consiste na criação de vários blocos e da possibilidade na não universalização dos valores, que são distintos, e por isso devem ser revistos para além da lente ocidental de criação dos direitos reconhecidos enquanto universais e por isso inexequíveis.

$\mathrm{Na}$ verdade, Mouffe sugere a necessidade de aceitar diferentes modelos de democracia em um mundo multipolar, na sustentação da importância do político enquanto sujeito ativo e partícipe das instâncias representativas do mundo no qual ele se insere. Isso significa uma 'politização da política', construída no ponto de interseção de uma pluralidade de posições, sendo isso o que vem endossar a possibilidade de repensar uma política democrática radical e plural, que coloque no centro do debate atual a relação antagônica entre diferentes subjetividades políticas articuladas no cenário mundial.

\footnotetext{
${ }^{24}$ Ibid., p. 125

${ }^{25}$ Ibid., p. 59.
} 


\section{Referências bibliográficas:}

BOBBIO, Norberto. Sobre el fundamento de los derechos del hombre. In: $E l$ tiempo de los derechos. Madrid: Sistema, 1991.

CASSIARI, Massimo. Digressoni su Impero e ter Rome. In: H. Frise; A. Negri; P. Wagner (eds). Europa política ragioni di una necessita. Roma: Manifestolibri, 2002.

DOUZINAS, Costas. Os paradoxos dos direitos humanos. Tradução de Caius Brandão. Revista Anuário. Pensar os direitos humanos: desafios à educação nas sociedades democráticas, v. 1, n.1, 2001.

O fim dos direitos humanos. Tradução de Luzia Araújo. São Leopoldo: Unisinos, 2009.

ENZENSBERGER, Hans Magnus. Visões da guerra civil. In: Guerra civil. São Paulo: Cia das Letras, 1995.

GUNTHER, Klaus. Der Sinn für Angemessenheit. Anwendungsdiskurse. In Moral und Recht. Frankfurt: Suhrkamp, 1988.

HABERMAS, Jurgen. Direito e democracia: entre facticidade e validade. Tradução de Flávio Beno Siebeneichler. Rio de Janeiro: Tempo Brasileiro, 1997.

. A inclusão do outro. Estudos de teoria política. Tradução de George Sperber e Paulo Astor Soethe. São Paulo: Loyola, 2002.

KERSTING, Wolfgang. Em defesa de um universalismo sóbrio. In:

Universalismo e direitos humanos. Porto Alegre: EDIPUCRS, 2003.

LÈVINAS, Emmanuel. Totalidad e infinito. Ensayo sobre la exterioridad. 2. ed. Salamanca: Sígueme, 1987.

Humanismo do outro homem. Tradução de Pergentino S. Pivato. Petrópolis: Vozes. 1993.

MOUFFE, Chantal; LACLAU, Ernesto. Hegemonía y estrategia socialista. Hacia una radicalización de la democracia. Madrid: Siglo XXI, 1987.

El retorno de lo político. Comunidade, ciudadanía, pluralismo

e democracia radical. Traducción de Marco Aurelio Galmarini. Buenos Aires: Paidós, 1999.

La paradoxa democrática. Traducción de Tomás Fernández e

Beatriz Equibar. Barcelona: Gedisa, 2003. En torno a lo político. Buenos Aires: Fondo de Cultura Económica, 2009.

SCHMITT, Carl. The concept of the political. New Brunswick: Rutgers, 1976.

STATEN, Henry. Wittgenstein and Derrida. Lincoln: University of Nebraska Press, 1984. 